\title{
Rotational angiography with 3D reconstruction: new imaging method in electrophysiology in University Hospital Centre Zagreb
}

\author{
Mislav Puljević*, \\ Davor Puljević, \\ Borka Pezo-Nikolić, \\ Vedran Velagić
}

University of Zagreb School of Medicine, University Hospital Centre Zagreb, Zagreb, Croatia
RECEIVED:

July 29, 2015

ACCEPTED:

September 17, 2015

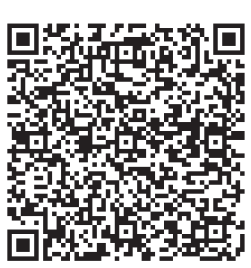

KEYWORDS: 3D reconstruction, electrophysiology, cryoablation.

CITATION: Cardiol Croat. 2015;10(9-10):232. | DOI: http://dx.doi.org/10.15836/ccar.2015.232

*ADDRESS FOR CORRESPONDENCE: Mislav Puljević, Klinički bolnički centar Zagreb, Kišpatićeva 12, HR-10000 Zagreb, Croatia. / Phone: +385-91-4680-414 / E-mail: puljevicmislav@gmail.com

ORCID: Mislav Puljević, http://orcid.org/0000-0003-1477-2581 • Davor Puljević, http://orcid.org/0000-0003-3603-2242 Borka Pezo-Nikolić, http://orcid.org/0000-0002-0504-5238 •Vedran Velagić, http://orcid.org/0000-0001-5425-5840

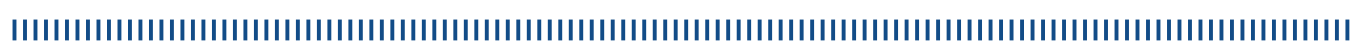

For ablation of some arrhythmias exact knowledge of anatomy structure which is planned for ablation or relations with the surrounding structures is very important. Two examples of such arrhythmias are atrial fibrillation (AF) and ventricular tachycardia (VT) from the aortic root. For the AF it is important to know the exact anatomy and variations of the position and shape of the pulmonary veins (common trunk left vein, 5 veins, etc.), in order to select the most optimal method of ablation. In VT from the aortic cusps it is necessary to know the exact distance from the focus to the orifice of the coronary arteries (possible lesion of coronary artery). For this purpose in most centers CT angiography or NMR with reconstruction are performed before electrophysiology (EP) procedure. Newer simpler and cheaper method is rotational angiography with 3D reconstruction. ${ }^{1}$ During the EP procedure, on the same $\mathrm{X}$-ray device, it is possible to make a 3D reconstruction of specific heart structure. Reconstructed image can be then quickly imported to live fluoroscopic image. On this superponed picture live catheter position is clearly seen, you can easily determine direction of catheter for easier entering of certain vein, whether cryoballoon is on PV ostium or too deep, where exactly atrial appendage is etc. During EP procedure of VT from the aortic cusps, 3D reconstruction shows aortic root and additionally coronary arteries ostias. Superponed 3D image synchronously moves with "live" fluoroscopic image so it is possible to see exactly position of mapping catheter in regard to coronary artery ostium or aortic valve. On reconstructed image it is possible to tag points, draw lines and measure in exact superposition to "live" image. Using this method ablation can be easier, faster and more secure. This new method is available in new EP lab at University Hospital Center Zagreb. The first experiences with this new method are very positive, and benefit is clearly depicted in this two examples (AF and VT).

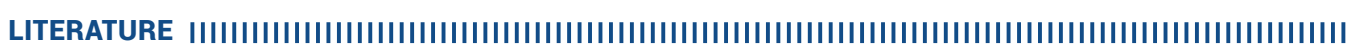

1. Orlov MV, Hoffmeister P, Chaudhry GM, Almasry I, Gijsbers GH, Swack T, et al. Three-dimensional rotational angiography of the left atrium and esophagus -- A virtual computed tomography scan in the electrophysiology lab? Heart Rhythm. 2007;4:37-43. DOI: http://dx.doi.org/10.1016/..hrthm.2006.10.003 